\title{
Chronic stress at work and the metabolic syndrome: prospective study
}

Tarani Chandola, Eric Brunner, Michael Marmot

\begin{abstract}
Objectives To investigate the association between stress at work and the metabolic syndrome.

Design Prospective cohort study investigating the association between work stress and the metabolic syndrome.

Participants 10308 men and women, aged 35-55, employed in 20 London civil service departments at baseline (the Whitehall II study); follow-up was an average of 14 years.

Main outcome measures Work stress based on the iso-strain model, measured on four occasions (1985-99). Biological measures of the metabolic syndrome, based on the National Cholesterol Education Program definition, measured in 1997-9. Results A dose-response relation was found between exposure to work stressors over 14 years and risk of the metabolic syndrome, independent of other relevant risk factors.

Employees with chronic work stress (three or more exposures) were more than twice as likely to have the syndrome than those without work stress (odds ratio adjusted for age and employment grade $2.25,95 \%$ confidence interval 1.31 to 3.85 ). Conclusions Stress at work is an important risk factor for the metabolic syndrome. The study provides evidence for the biological plausibility of the link between psychosocial stressors from everyday life and heart disease.
\end{abstract}

\section{Introduction}

Stress at work has been linked with coronary heart disease in retrospective and prospective studies. ${ }^{12}$ The biological mechanisms remain unclear. ${ }^{3}$ Plausible pathophysiological mechanisms involve direct neuroendocrine effects and indirect effects mediated by adverse health behaviours. ${ }^{4-6}$

The metabolic syndrome is a cluster of risk factors that increases the risk of heart disease and type 2 diabetes. ${ }^{7}$ Characteristics of the metabolic syndrome are abdominal obesity, atherogenic dyslipidaemia (raised triglycerides, small low density lipoprotein particles, and low concentrations of high density lipoprotein cholesterol), high blood pressure, insulin resistance (with or without glucose intolerance), and prothrombotic and proinflammatory states (table 1). Previous studies found a social gradient in work stress and the metabolic syndrome,${ }^{89}$ suggesting that the social gradient in the metabolic syndrome and heart disease could in part be explained by greater exposure to work stress among less advantaged social groups. Cross sectional studies have linked work stress with components of the syndrome, ${ }^{1011}$ but this association is not consistent. ${ }^{42}$

A major limitation of previous studies is the lack of information on the duration of exposure to work stress. Repeated meas- urements of work stress over a person's career provide a more accurate representation of exposure to psychosocial stress, and its cumulative effect on health. ${ }^{13}$ Here, we report the association between work stress (measured in four phases) and the metabolic syndrome over 14 years of follow-up, and we test the hypothesis of a dose-response association. If the prospective stressmetabolic syndrome relation is robust to adjustment for confounders (such as social position) and potential mediators (such as health behaviours) a stronger causal inference could be made.

\section{Methods}

The Whitehall II study recruited participants from 20 civil service departments in London from 1985 to 1988 (phase 1). Surveys consisted of postal questionnaires in 1989 (phase 2), 1991-3 (phase 3, which also included a clinical examination), 1995 (phase 4), and 1997-9 (phase 5, which also included a clinical examination). The phase 4 questionnaire collected no information on work stress or health behaviours. Full details of the screening examinations are reported elsewhere. ${ }^{14}$

\section{Variables}

Data on the components of the metabolic syndrome were collected at phase 5 (1997-9) during the clinical examination, using the definition of the National Cholesterol Education Program (adult treatment panel III) (table 1). ${ }^{7}$ The syndrome was defined by the presence of three or more risk factors. Components of the metabolic syndrome were not measured at baseline. We used obesity (defined as body mass index >30) at baseline as an indicator of risk for the syndrome.

We measured self reported work stress using the job strain questionnaire. ${ }^{15}$ Work stress was present when participants' responses to questions about the job demands were high and

Table 1 Definition of the metabolic syndrome. ${ }^{*}$ Three risk factors need to be present

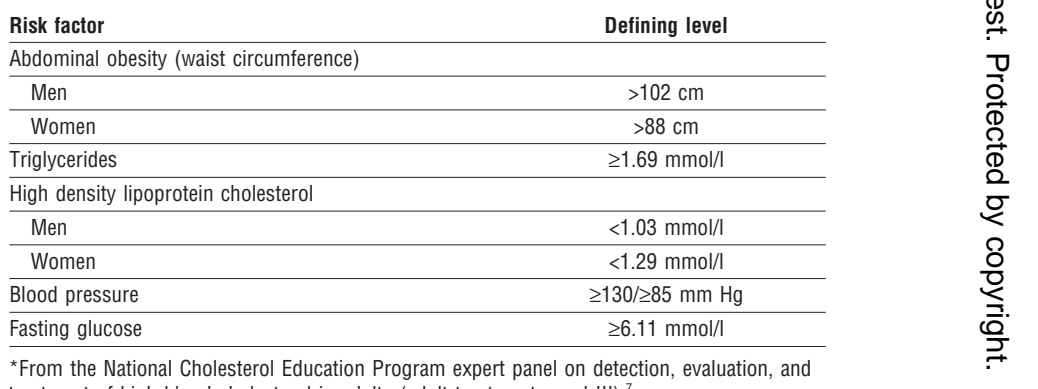

*From the National Cholesterol Education Program expert panel on detection, evaluation, and treatment of high blood cholesterol in adults (adult treatment panel III). 
Table 2 Risk factors for having the metabolic syndrome by explanatory variables. Bivariate logistic regression models: complete case analysis

\begin{tabular}{|c|c|c|c|c|c|}
\hline \multirow{2}{*}{ Explanatory variables } & \multicolumn{2}{|c|}{ Men } & \multicolumn{2}{|c|}{ Women } & \multirow{2}{*}{ Sex interaction* } \\
\hline & No of cases/total & Odds ratios $(95 \% \mathrm{CI})$ & No of cases/total & Odds ratios $(95 \% \mathrm{Cl})$ & \\
\hline Age group, phase 1: & $425 / 4583$ & & $172 / 1869$ & & $<0.01$ \\
\hline $35-39$ & $122 / 1351$ & 1.00 & $36 / 490$ & 1.00 & \\
\hline $40-44$ & $118 / 1250$ & 1.05 (0.81 to 1.37$)$ & $28 / 479$ & 0.78 (0.47 to 1.31$)$ & \\
\hline $45-49$ & $88 / 878$ & 1.12 (0.84 to 1.50$)$ & $42 / 400$ & 1.48 (0.93 to 2.36$)$ & \\
\hline$\geq 50$ & $97 / 1104$ & 0.97 (0.73 to 1.28) & $66 / 500$ & 1.92 (1.25 to 2.94$)$ & \\
\hline$\geq P$ for linear trend & & 0.96 & & $<0.01$ & \\
\hline Employment grade, phase 1: & $425 / 4583$ & & $172 / 1869$ & & 0.42 \\
\hline High & $160 / 1909$ & 1.00 & $13 / 280$ & 1.00 & \\
\hline Intermediate & $222 / 2383$ & 1.12 (0.91 to 1.39$)$ & $62 / 821$ & 1.67 (0.91 to 3.09) & \\
\hline Low & $43 / 291$ & 1.90 (1.32 to 2.72) & $97 / 768$ & 2.96 (1.63 to 5.37) & \\
\hline $\mathrm{P}$ for linear trend & & 0.01 & & $<0.01$ & \\
\hline Work stress, over 4 phases: & $216 / 2433$ & & $64 / 813$ & & 0.46 \\
\hline No exposures & $146 / 1777$ & 1.00 & $42 / 616$ & 1.00 & \\
\hline 1 exposure & $43 / 449$ & 1.18 (0.83 to 1.69$)$ & $11 / 131$ & 1.25 (0.63 to 2.50$)$ & \\
\hline 2 exposures & $15 / 125$ & 1.52 (0.87 to 2.68) & $6 / 48$ & 1.95 (0.78 to 4.85$)$ & \\
\hline$\geq 3$ exposures & $12 / 82$ & 1.91 (1.01 to 3.61) & $5 / 18$ & 5.26 (1.79 to 15.44) & \\
\hline $\mathrm{P}$ for linear trend & & 0.02 & & $<0.01$ & \\
\hline No fruit and veg, over 4 phases: & $345 / 3854$ & & $140 / 1538$ & & 0.75 \\
\hline No exposures & $109 / 1396$ & 1.00 & $63 / 716$ & 1.00 & \\
\hline 1 exposure & $69 / 803$ & 1.11 (0.81 to 1.52$)$ & $24 / 302$ & 0.89 (0.55 to 1.46$)$ & \\
\hline 2 exposures & $50 / 596$ & 1.08 (0.76 to 1.53$)$ & $16 / 222$ & 0.81 (0.46 to 1.42$)$ & \\
\hline$\geq 3$ exposures & $117 / 1059$ & 1.47 (1.11 to 1.93$)$ & $37 / 298$ & 1.47 (0.96 to 2.26$)$ & \\
\hline $\mathrm{P}$ for linear trend & & 0.01 & & $<0.01$ & \\
\hline Heavy drinker, over 4 phases: & $341 / 3839$ & & $140 / 1527$ & & 0.02 \\
\hline No exposures & $231 / 2940$ & 1.00 & $132 / 1357$ & 1.00 & \\
\hline 1 exposure & $44 / 410$ & 1.41 (1.00 to 1.98$)$ & $3 / 109$ & 0.26 (0.08 to 0.84$)$ & \\
\hline 2 exposures & $19 / 194$ & 1.27 (0.78 to 2.08$)$ & $1 / 30$ & 0.32 (0.04 to 2.37) & \\
\hline$\geq 3$ exposures & $47 / 295$ & 2.22 (1.58 to 3.12$)$ & $4 / 31$ & 1.37 (0.47 to 3.99$)$ & \\
\hline$P$ for linear trend & & $<0.01$ & & 0.26 & \\
\hline Current smoker, over 4 phases: & $354 / 3925$ & & $146 / 1580$ & & 1.00 \\
\hline No exposures & $286 / 3366$ & 1.00 & $112 / 1294$ & 1.00 & \\
\hline 1 exposure & $14 / 118$ & 1.45 (0.82 to 2.57$)$ & $6 / 51$ & 1.41 (0.59 to 3.37$)$ & \\
\hline 2 exposures & $10 / 83$ & 1.48 (0.75 to 2.89$)$ & $4 / 35$ & 1.36 (0.47 to 3.93) & \\
\hline$\geq 3$ exposures & $44 / 358$ & 1.51 (1.08 to 2.12) & $24 / 200$ & $1.44(0.90 .2 .30)$ & \\
\hline $\mathrm{P}$ for linear trend & & 0.01 & & $<0.01$ & \\
\hline No exercise, over 4 phases: & $281 / 3313$ & & $99 / 1201$ & & 0.18 \\
\hline No exposures & $45 / 796$ & 1.00 & $7 / 90$ & 1.00 & \\
\hline 1 exposure & $59 / 641$ & 1.69 (1.13 to 2.53$)$ & $6 / 133$ & 0.56 (0.18 to 1.73$)$ & \\
\hline 2 exposures & $44 / 562$ & 1.42 (0.92 to 2.18$)$ & $7 / 159$ & 0.55 (0.19 to 1.61$)$ & \\
\hline$\geq 3$ exposures & $133 / 1314$ & 1.88 (1.32 to 2.67) & $79 / 819$ & 1.27 (0.57 to 2.83) & \\
\hline $\mathrm{P}$ for linear trend & & $<0.01$ & & $<0.01$ & \\
\hline Obese, phase 1: & $425 / 4583$ & & $172 / 1869$ & & 0.52 \\
\hline No & $357 / 4399$ & 1.00 & $114 / 1707$ & 1.00 & \\
\hline Yes & $68 / 184$ & 6.64 (4.83 to 9.12$)$ & $58 / 162$ & 7.79 (5.36 to 11.32) & \\
\hline $\mathrm{P}$ for linear trend & & $<0.01$ & & $<0.01$ & \\
\hline
\end{tabular}

*Probability that the interaction of sex with the explanatory variable reduces the deviance.

those to questions about decision latitude (job control) were low (defined as above or below the median score for the measures of "job demands" and "job decision latitude"). The iso-strain model is one of several variants of this concept of work stress; this model hypothesises that socially isolated (that is, no supportive coworkers or supervisors) high job strain carries the highest risk for heart disease. Iso-strain is a parsimonious instrument for measuring and analysing workplace conditions. ${ }^{16}$ We defined participants in the lowest third of work social support who reported job strain (high job demands and low job control) as having work stress ${ }^{17}$ and measured the accumulation of exposure to work stress over the four measurement periods (phases 1,2,3, and 5 ) by adding together the number of times the participant was exposed to iso-strain. We defined chronic work stress as experiencing iso-strain three or more times ( $>75 \%$ of the time) over the 14 year study period. Participants who lacked work stress data at any of the phases of data collection were given a missing value.

We measured social position using the relative index of inequality, based on employment grade at baseline. Values of 0 and 1 correspond to subjects who are at the top and bottom of the socioeconomic hierarchy. The health behaviours (all self reported) analysed were: current smoking, no daily fruit and vegetable consumption, heavy alcohol consumption (men $>4$ units/day, women $>3$ units/day), and no exercise. We summed exposure to these health damaging behaviours over the four measurement periods (phases 1, 2, 3, and 5) and assigned a missing value to participants who lacked data on a specific health behaviour at any of the time periods. 
Research

Table 3 Odds ratios (95\% confidence intervals) of the metabolic syndrome. Multivariate multiple imputation logistic regression models: non-retired men and women in the Whitehall II cohort at phase 5

\begin{tabular}{|c|c|c|c|c|c|}
\hline & \multicolumn{3}{|c|}{ Including patients who were obese at baseline } & \multicolumn{2}{|c|}{ Excluding patients who were obese at baseline } \\
\hline & No of cases/total & $\begin{array}{c}\text { Adjusted for } \\
\text { age+employment grade }\end{array}$ & $\begin{array}{l}\text { Adjusted for age+employment } \\
\text { grade+health behaviours }\end{array}$ & No of cases/total & $\begin{array}{l}\text { Adjusted for age+employment } \\
\text { grade+health behaviours }\end{array}$ \\
\hline \multicolumn{6}{|l|}{ Men and women: } \\
\hline No exposures & $491 / 5178$ & 1.00 & 1.00 & $388 / 4881$ & 1.00 \\
\hline 1 exposure & $134 / 1253$ & 1.13 (0.70 to 1.82$)$ & $1.12(0.70$ to 1.82$)$ & $103 / 1165$ & 1.11 (0.60 to 2.03$)$ \\
\hline 2 exposures & $54 / 383$ & 1.55 (0.85 to 2.85$)$ & 1.53 (0.87 to 2.69$)$ & $41 / 356$ & 1.47 (0.74 to 2.92$)$ \\
\hline$\geq 3$ exposures & $41 / 220$ & 2.25 (1.31 to 3.85$)$ & 2.39 (1.36 to 4.21$)$ & $30 / 198$ & 2.29 (1.27 to 4.12$)$ \\
\hline $\mathrm{P}$ for linear trend & & $<0.01$ & $<0.00$ & & 0.01 \\
\hline \multicolumn{6}{|l|}{ Men: } \\
\hline No exposures & $341 / 3564$ & 1.00 & 1.00 & $281 / 3407$ & 1.00 \\
\hline 1 exposure & $95 / 900$ & 1.11 (0.73 to 1.67$)$ & $1.11(0.73$ to 1.69$)$ & $77 / 851$ & 1.12 (0.67 to 1.87$)$ \\
\hline 2 exposures & $37 / 252$ & 1.64 (0.98 to 2.73$)$ & 1.57 (0.92 to 2.65$)$ & $31 / 238$ & 1.56 (0.93 to 2.63$)$ \\
\hline$\geq 3$ exposures & $32 / 181$ & 2.01 (0.88 to 4.58$)$ & 2.17 (0.92 to 5.09$)$ & $24 / 166$ & 2.04 (0.86 to 4.85$)$ \\
\hline $\mathrm{P}$ for linear trend & & 0.03 & 0.03 & & 0.04 \\
\hline \multicolumn{6}{|l|}{ Women: } \\
\hline No exposures & $150 / 1614$ & 1.00 & 1.00 & $107 / 1474$ & 1.00 \\
\hline 1 exposure & $40 / 353$ & 1.23 (0.40 to 3.74$)$ & 1.27 (0.42 to 3.84$)$ & $25 / 314$ & 1.22 (0.28 to 5.37$)$ \\
\hline 2 exposures & $17 / 131$ & 1.27 (0.34 to 4.83$)$ & 1.45 (0.45 to 4.75$)$ & $10 / 118$ & 1.09 (0.15 to 7.94$)$ \\
\hline$\geq 3$ exposures & $9 / 39$ & 3.73 (0.88 to 15.75$)$ & 3.72 (0.79 to 17.53$)$ & $6 / 32$ & 4.69 (0.79 to 27.86) \\
\hline $\mathrm{P}$ for linear trend & & 0.23 & 0.11 & & 0.26 \\
\hline
\end{tabular}

\section{Analysis}

We used logistic regression analysis to assess the odds ratios of the metabolic syndrome for the different explanatory variables and nested logistic regression models to examine the effect of adjusting for different explanatory variables. We excluded 70 patients with heart disease (non-fatal myocardial infarction) at baseline from all the analyses and in some analyses also excluded the 717 obese (body mass index $>30$ ) patients at baseline, to test the causal direction from work stress to the metabolic syndrome and associated obesity.

\section{Missing data and cohort dropout}

The first phase of the Whitehall II study (1985-8) comprised 10308 civil servants. By phase 5 of the study (1997), the participation rate was $75 \%$, taking into account 488 deaths among the 7357 participants at this stage; 5882 had complete clinical data on the indicators of the metabolic syndrome.

Our missing data analysis procedures used missing at random (MAR) assumptions. We used the MICE (multivariate imputation by chained equations) method of multiple multivariate imputation in STATA. ${ }^{18}{ }^{19}$ We independently analysed 10 copies of the data, each with missing values suitably imputed, in the multivariate logistic regression analyses. We averaged estimates of the variables to give a single mean estimate and adjusted standard errors according to Rubin's rules. ${ }^{20}$

A missing value on the work stress measure could indicate that the data were not available at a particular phase, the participant dropped out, or the participant was not in employment. In the last situation, the imputed values for the work stress variables include non-applicable values for respondents who had retired from work by phase 5 . Hence, we analysed only those respondents who had not retired by phase 5 (imputed $n=7034$ out of 10238 ) in the multivariate models using the imputed data. Participants who were in employment and had never experienced work stress during the 14 years formed the reference group for the work stress measure for both the complete cases and imputed analyses.

\section{Results}

Table 2 shows bivariate analyses of the association between the metabolic syndrome and each of the explanatory variables, with separate analyses for men and women. Age was a risk factor among women but not men (interaction $\mathrm{P}<0.01$ ). Both men and women from lower employment grades were more likely to have the syndrome. We found a dose-response relation between exposure to job stress and the syndrome (trend $\mathrm{P}<0.05$ for men; $\mathrm{P}<0.01$ for women). Men with chronic work stress (three or more exposures) were nearly twice as likely to develop the metabolic syndrome than those with no exposure to work stress. Women with chronic work stress were over five times more likely to have the metabolic syndrome, but they formed a small group $(\mathrm{n}=18)$.

The association between the metabolic syndrome and exposure to health damaging behaviours was stronger among men than women. Poor diet (no fruit and vegetable consumption), heavy alcohol consumption, smoking, and physical inactivity were associated with higher odds of the metabolic syndrome (see table 2).

Because few men and women had chronic exposure to work stress (three or more exposures) and the evidence for a sex difference in the effect of work stress on the metabolic syndrome was scarce, men and women were combined in the multivariate analysis of the dose-response effect of work stress. Examination of the effects of the interaction between sex and the explanatory variables showed little evidence of sex differences.

Table 3 shows the results of a series of nested multivariate logistic regression models of the metabolic syndrome. These models use imputed data. The analyses excluded respondents with pre-existing heart disease at baseline and those who had retired at phase 5 . In the model with men and women, adjusted for age and employment grade only, greater exposure to work stress was significantly associated with increasing odds of the syndrome. Adjusting for health behaviours did not change the dose-response association. When we excluded obese men and women at baseline (using obesity as a proxy indicator of the syndrome at baseline), the linear association between work stress and the metabolic syndrome remained. When we analysed men and women separately, the pattern of effects was similar, although for women the small number of cases resulted in a non-significant association.

The metabolic syndrome showed a social gradient: men and women in the lowest employment grades had more than double 
Table 4 Risk of having the metabolic syndrome by relative index of inequality of employment grade. Multivariate multiple imputation logistic regression models: non-retired men and women in the Whitehall II cohort at phase 5

\begin{tabular}{lccc} 
& $\begin{array}{c}\text { Odds ratio } \\
(\mathbf{9 5 \%} \mathbf{~ C l})\end{array}$ & $\mathbf{P}$ for linear trend & $\begin{array}{c}\text { Reduction in log } \\
\text { odds from model I }\end{array}$ \\
\hline Age+sex (model I) & $\begin{array}{c}2.33 \\
(1.38 \text { to } 3.93)\end{array}$ & $<0.01$ & \\
\hline Age+sex+work stress & 2.13 & 0.01 & $10.5 \%$ \\
& $(1.22$ to 3.71$)$ & & $15.6 \%$ \\
\hline Age+sex+health behaviours & 2.04 & 0.04 & \\
\hline $\begin{array}{l}\text { Age+sex+work } \\
\text { stress+behaviours }\end{array}$ & $\begin{array}{c}1.05 \text { to } 3.95) \\
(0.96 \text { to } 3.61)\end{array}$ & 0.07 & $26.4 \%$ \\
\hline
\end{tabular}

the odds of the syndrome than those in the highest grades (odds ratio 2.33; table 4). When we adjusted the figures for work stress, the difference in the log odds between the highest and lowest employment grades was reduced by $11 \%$. Adjusting for health behaviours reduced the social gradient by around $16 \%$. When adjusted for health behaviours and work stress the social gradient was non-significant $(\mathrm{P}=0.07)$.

\section{Discussion}

\section{Main findings}

Greater exposure to job stress over 14 years was linked to greater risk of the metabolic syndrome, in a dose-response manner. The association was robust to adjustment for occupational status and health behaviours. These prospective findings are evidence of the biological plausibility of a causal association between chronic psychosocial stress and the risk of chronic heart disease. Crucially, by excluding participants who were obese at baseline, we showed that pre-existing physiological risk is unlikely to explain the observed association. Furthermore, the social gradient in the metabolic syndrome is partially explained by work stress and a larger proportion is explained by health behaviours.

By characterising work stress exposure with multiple measures, we have conducted an innovative and rigorous study of the cumulative effect of psychosocial adversity on the clustering of coronary risk factors. It is unclear whether the development of risk seen here is due in part to the direct effects of chronic stress on insulin resistance, resting blood pressure, and lipoprotein metabolism, although this interpretation is supported by Whitehall II and other studies. ${ }^{35}{ }^{21}$ We took account of smoking habit, physical inactivity, poor diet, and excess alcohol intake with repeated measurements over the course of follow-up. Each of these adverse health behaviours predicted the risk of the metabolic syndrome in men and, less consistently, in women, but there was little evidence that these behaviours mediated or confounded the effect of work stress on the risk of developing the syndrome. The effect of chronic work stress on unhealthy behaviours remains a question for future research.

\section{Biology of stress}

Prolonged exposure to work stress may affect the autonomic nervous system and neuroendocrine activity directly, contributing to the development of the metabolic syndrome. A case-control study showed that participants in the Whitehall II study with the metabolic syndrome had raised cortisol and normetanephrine output, and also had reduced variability in heart rate. ${ }^{5}$ Decrements in cardiac autonomic function have been linked to the metabolic syndrome in other populations and to low job control and social isolation among men in the Whitehall II study. ${ }^{6223}$ Psychobiological studies have also shown that

\section{What is already known on this topic}

Stress at work is associated with coronary heart disease, but the biological mechanisms underlying this association are unclear

The metabolic syndrome has a social gradient

What this study adds

A dose-response association exists between exposure to work stress and the metabolic syndrome

The study provides evidence for the biological plausibility of psychosocial stress mechanisms linking stressors from everyday life with heart disease

Part of the social gradient in the metabolic syndrome is explained by chronic exposure to work stress

heightened stress reactivity and impaired recovery after stress, assessed by blood pressure and inflammatory markers, predict the five year progression of the metabolic syndrome. ${ }^{20}$ Chronic psychological stress may reduce biological resilience and thus disturb homoeostasis. Altered adrenocortical function can influence hepatic lipoprotein metabolism and insulin sensitivity at target organs. ${ }^{21}{ }^{24}$ Cortisol is an insulin antagonist, and cortisol output is increased in the metabolic syndrome. ${ }^{5}$ Low concentrations of high density lipoprotein cholesterol and glucose intolerance have been linked with high basal secretion of cortisol. ${ }^{25}$

\section{Limitations}

We were not able to analyse incidence because of the lack of data on all metabolic syndrome components at study baseline. Overweight people may be more socially isolated and may find working conditions more stressful. However, excluding obese participants at baseline did not change our findings. Missing data are a common problem in all cohort studies. Although the dropout rate between phases 1 and 5 of this study was high, we used analytical procedures that take account of missing data. The results using imputed data were in line with the results from the analysis of the complete cases. Few women had chronic exposure to work stress, necessitating the analysis of men and women together.

\section{Conclusions}

A dose-response association exists between exposure to work stress and the metabolic syndrome. Employees with chronic work stress have more than double the odds of the syndrome than those without work stress, after other risk factors are taken into account. The study provides evidence for the biological plausibility of psychosocial stress mechanisms linking stressors from everyday life with heart disease.

We thank all participating civil service departments and their welfare, personnel, and establishment officers; the Occupational Health and Safety Agency; the Council of Civil Service Unions; all participating civil servants in the Whitehall II study; and all members of the Whitehall II study team. We also thank the referees of this paper for their useful comments.

Contributors: TC wrote the first draft of the paper and did all the analyses. $\mathrm{EB}$ and MM wrote subsequent drafts and guided the analyses. TC is the guarantor.

Funding: The Whitehall II study was supported by grants from the Medical Research Council; Economic and Social Research Council; British Heart Foundation; Health and Safety Executive; Department of Health; National Heart Lung and Blood Institute (HL36310), US, NIH; National Institute on Aging (AG13196), US, NIH; Agency for Health Care Policy Research (HS06516); and the John D and Catherine T MacArthur Foundation 
Research Networks on Successful Midlife Development and Socioeconomic Status and Health. MM is supported by an MRC research professorship.

Competing interests: None declared.

Ethical approval: University College London Medical School committee on the ethics of human research.

1 Rosengren A, Hawken S, Ounpuu S, Sliwa K, Zubaid M, Almahmeed WA, et al. Association of psychosocial risk factors with risk of acute myocardial infarction in 11119 cases and 13648 controls from 52 countries (the INTERHEART study): case-contro study. Lancet 2004;364:953-62.

2 Marmot MG, Bosma H, Hemingway H, Brunner E, Stansfeld S. Contribution of job control and other risk factors to social variations in coronary heart disease. Lance 1997;350:235-40

3 Brunner EJ, Marmot MG. Social organisation, stress and health. In: Marmot MG, Wilkinson RG, eds. Social determinants of health. Oxford: Oxford University Press, 2006; $6-30$.

4 Vrijkotte TGM, van Doornen LJP, De Geus EJC. Work stress and metabolic and hemostatic risk factors. Psychosom Med 1999;61:796-805. 5 Brunner EJ, Hemingway H, Walker BR, Page M, Clarke P, Juneja M, et al. Adrenocorti-
cal, autonomic, and inflammatory causes of the metabolic syndrome-nested $\mathrm{cal}$, autonomic, and inflammatory causes of

6 Hemingway H, Shipley M, Brunner E, Britton A, Malik M, Marmot M. Does autonomic function link social position to coronary risk? The Whitehall II study. Circulation 2005;111:3071-7.

7 Expert Panel on Detection. Executive summary of the third report of the National Cholesterol Education Program (NCEP) expert panel on detection, evaluation, and treatment of high blood cholesterol in adults (adult treatment panel III). JAMA 2001:285:2486-97

8 Marmot MG, Davey Smith G, Stansfeld SA, Patel C, North F, Head J, et al. Health inequalities among British civil servants: the Whitehall II study. Lancet 1991:337:138793.

9 Brunner EJ, Marmot MG, Nanchahal K, Shipley MJ, Stansfeld SA, Juneja M, et al. Social inequality in coronary risk: central obesity and the metabolic syndrome. Evidence from the WII study. Diabetologia 1997;40:1341-9.

10 Siegrist J, Peter R. Chronic work stress is associated with atherogenic lipids and elevated fibrinogen in middle-aged men.J Intern Med 1997;242:149-56.

11 Peter R, Alfredsson L, Hammar N, Siegrist J, Theorell T, Westerholm P. High effort, low reward and cardiovascular risk factors in employed Swedish men and womenbaseline results from the WOLF study.J Epidemiol Community Health 1998:52:540-7.

12 Schnall PL, Landsbergis PA. Job strain and cardiovascular disease. Annu Rev Public Health 1994;15:381-411.

13 Chandola T, Siegrist J, Marmot M. Do changes in effort-reward imbalance at work contribute to an explanation of the social gradient in angina? Occup Environ Med 2005;62:223-30.

14 Marmot MG, Brunner E. Cohort profile: the Whitehall II study. Int J Epidemiol 2005;34:251-6.
15 Karasek R, Theorell T. Healthy work:stress, productivity, and the reconstruction of working life. New York: Basic Books, 1990.

16 Landsbergis PA, Schnall PL, Warren K, Pickering TG, Schwartz JE. Association between ambulatory blood pressure and alternative formulations of job strain. Scand J Work Environ Health 1994;20:349-63.

17 Kuper H, Marmot M, Hemingway H. Systematic review of prospective cohort studies of psychosocial factors in the etiology and prognosis of coronary heart disease. Semin Vasc Med 2002;2:267-314.

18 Van Buuren S, Boshuizen HC, Knook DL. Multiple imputation of missing blood pressure covariates in survival analysis. Stat Med 1999;18:681-94.

19 Royston P. Multiple imputation of missing values. Stata J 2004;4:227-41.

20 Rubin DB. Multiple imputation for non-response in surveys. New York: John Wiley, 1987.

21 Steptoe A, Brunner E, Marmot M. Stress-induced inflammatory responses and risk of the metabolic syndrome: a longitudinal analysis. Obes Res 2004;12:A76.

22 Liao DP, Evans G, Arnett D, Pankow J, Liese A, Davis CE, et al. Multiple metabolic syndrome is associated with increased arterial stiffness-the ARIC study. Circulation 1998;97:828.

23 Singh JP, Larson MG, O'Donnell CJ, Wilson PF, Tsuji H, Lloyd-Jones DM, et al. Association of hyperglycemia with reduced heart rate variability (the Framingham heart study). Am J Cardiol 2000;86:309-12.

24 Bjorntorp P. Visceral fat accumulation-the missing link between psychosocial factors and cardiovascular disease. J Intern Med 1991;230:195-201.

25 Phillips DIW, Barker DJP, Fall CHD, Seckl JR, Whorwood CB, Wood PJ, et al. Elevated plasma cortisol concentrations: a link between low birth weight and the insulin resistance syndrome? J Clin Endocrinol Metab 1998;83:757-60.

(Accepted 17 November 2005)

doi $10.1136 /$ bmj.38693.435301.80

Department of Epidemiology and Public Health, University College London, London WC1E 6BT

Tarani Chandola senior lecturer

Eric Brunner reader

Michael Marmot head of group and department

Correspondence to: T Chandola t.chandola@ucl.ac.uk

\section{Amendment}

This is version 2 of the paper. In this version, the $95 \%$ confidence intervals in table 4 have been corrected. 